\title{
Reopening the doors of Dutch nursing homes during the COVID-19 crisis: results of an in-depth monitoring
}

\author{
Raymond T. C. M. Koopmans, 1,2 Hilde Verbeek, ${ }^{3}$ Annemiek Bielderman, ${ }^{1}$ \\ Meriam M. Janssen, ${ }^{4}$ Anke Persoon, ${ }^{1}$ Ivonne Lesman-Leegte, ${ }^{5}$ Eefje M. Sizoo, ${ }^{6}$ \\ Jan P. H. Hamers, ${ }^{3}$ and Debby L. Gerritsen ${ }^{1}$ \\ ${ }^{1}$ Department of Primary and Community Care, Radboud University Nijmegen, Medical Center, Nijmegen, the Netherlands \\ ${ }^{2}$ De Waalboog "Foachim en Anna," Center for Specialized Geriatric Care, Nijmegen, the Netherlands \\ ${ }^{3}$ Department of Health Services Research, Care and Public Health Research Institute, Maastricht University, Maastricht, the Netherlands; Living Lab in Ageing \\ and Long-Term Care, Maastricht, the Netherlands \\ ${ }^{4}$ Tranzo Department, Scientific Center for Care and Welfare, Tilburg University, Tilburg, the Netherlands \\ ${ }^{5}$ Department of General Practice and Elderly Care Medicine, University of Groningen, University Medical Center Groningen, Groningen, the Netherlands \\ ${ }^{6}$ Department of Medicine for Older People, Amsterdam Public Health Research Institute, Amsterdam University Medical Centers, Location VUmc, Amsterdam, \\ the Netherlands
}

ABSTRACT

Objectives: On May 11, the Dutch Government allowed 26 nursing homes to welcome 1 visitor per resident, after 2 months of lockdown. The study aimed to monitor in-depth the feasibility of the regulations and their impact on the well-being of residents, their visitors, and healthcare staff.

Design: Mixed-methods study in 5 of the 26 facilities; the facilities were affiliated to an academic network of nursing homes.

Participants: Visitors and healthcare professionals.

Intervention: Allowing visitors using local regulations based on national guidelines.

Measurements: Digital questionnaire, analyzing documentation such as infection prevention control protocols, attending meetings of COVID-19 crisis teams, in-depth telephone or in-person interviews with visitors and healthcare professionals, and on-site observations.

Results: National guidelines were translated with great variety into local care practice. Healthcare professionals agreed that reopening would increase the well-being of the residents and their loved ones. However, there were also great worries for increasing workload, increasing the risk of emotional exhaustion, and the risk of COVID-19 infections. Compliance with local regulations was generally satisfactory, but maintaining social distance and correctly wearing face masks appeared to be difficult. Care staff remained ambivalent for fear of infections. In general, allowing visitors was experienced as having a positive impact on the well-being of all stakeholders. Nevertheless, some residents with dementia showed negative effects.

Conclusion: The complete lockdown of Dutch nursing homes had a substantial impact on the well-being of the residents. The reopening was welcomed by all stakeholders, but provided a high organizational workload as well as feelings of ambivalence among care staff. In the second wave, a more tailored approach is being implemented. However, facilities are sometimes still struggling to find the right balance between infection control and well-being.

key words: qualitative research, quality of life (QoL), nursing homes, neuropsychiatric symptoms

Correspondence should be addressed to: Raymond TCM Koopmans, Department of Primary and Community Care, Radboud University Medical Center, Nijmegen, P.O. Box 9101, 6500 HB Nijmegen, the Netherlands. Phone: +31243614036. Email: Raymond.Koopmans@radboudumc.nl. Received 01 Dec 2020; revision requested 05 Jan 2021; revised version received 03 Feb 2021; accepted 11 Feb 2021. First published online 05 April 2021.

\section{Introduction}

Residents of nursing homes are particularly at risk of being infected with COVID-19 and have high rates of mortality as a result (Rutten et al., 2020). For that reason, the Dutch Government, like many other countries in Europe, decided to close the doors to visitors of all skilled nursing facilities and facilities for small-scale housing as of March 20, 2020. Care 
staff showing no typical COVID-19 symptoms were allowed to care for the residents. However, physicians, psychologists, and other professionals like physiotherapists or occupational therapists minimized the amount of direct resident contact, limited travels between facilities, and performed consults by telephone or video whenever possible (Car et al., 2020).

The impact of putting residents under quarantine has been described previously. A survey about challenging behavior among 323 psychologists and elderly care physicians working in Dutch nursing homes showed reported increases as well as decreases in rates of challenging behavior as well as initial decreases followed by an increase, and vice versa (Leontjevas et al., 2020). Furthermore, the participants reported more apathy and depressive symptoms. Comparable studies found high rates of loneliness, depression, exacerbation of behavioral problems, and decrease in quality of life (Simonetti et al., 2020; Van der Roest et al., 2020; Wammes et al., 2020). Although quarantine is a necessary measure to prevent the virus to spread, it also leads to loneliness and social isolation (Hwang et al., 2020) that are independent risk factors for all-cause mortality (Yu et al., 2020). Indeed, there are anecdotal stories of healthcare professionals stating that residents died because of a lack of visits from their loved ones. The impact on the mental health of care home residents with dementia, who comprise around $70 \%$ of the Dutch nursing home population, is even more significant (Velayudhan et al., 2020; Wang et al., 2020). Extreme challenging behavior and severe suffering of residents have been reported, facing healthcare professionals with the (ethical) dilemma of whether or not to allow family members to visit in order to calm down the resident and provide support (Sizoo et al., 2020). Although digital solutions such as FaceTime are promising interventions to alleviate the absence of family, these cannot replace human physical contact, especially for residents with dementia in the advanced stages (Padala et al., 2020). Thus, nursing homes are struggling to find a balance between infection management and residents' mental health needs (Dichter et al., 2020).

Eight weeks after the start of lockdown, the Ministry of Health, Welfare and Sports initiated a national pilot, starting May 11, to lift the ban in nursing homes in a selection of 26 nursing homes. In these 26 facilities, global scientific monitoring was performed using electronic questionnaires with additional telephone interviews of a dedicated contact person. The first results after 1 week of this pilot have been published elsewhere (Verbeek, Gerritsen, et al., 2020). In this study, a great variation in local protocols was found regarding, for instance, the use of personal protective equipment. Allowing visitors again and therefore restoring personal contact was experienced as being of great value and had a positive effect on well- being. In this paper, we report the results of the first 3 weeks of in-depth monitoring of reopening the doors of Dutch nursing homes regarding the feasibility of the regulations and impact on the well-being of residents, their visitors, and healthcare staff.

\section{Methods}

This study was a mixed-methods study. Five of the 26 facilities of the global monitoring were invited to participate in the in-depth monitoring. All were affiliated to one of the Dutch academic nursing home networks (Koopmans et al., 2013; Verbeek et al., 2013; Verbeek, Zwakhalen, et al., 2020). Three were located in relatively highly affected regions in the Netherlands.

For studying feasibility, we used the framework for process evaluation of Leontjevas et al. focusing on the reach of the regulations for reopening, fidelity (compliance with local regulations), attitudes toward reopening, strategies used for implementation, and encountered barriers and facilitators (Appelhof et al., 2018; Leontjevas et al., 2012). To assess feasibility, we analyzed documentation such as infection prevention control protocols and the contents of the local visitors' regulations, attended meetings of COVID-19 crisis teams, and conducted in-depth telephone or in-person interviews with visitors and healthcare professionals. In addition, on-site observations, using a pre-structured observation form, were conducted in the communal areas of the nursing home, especially near the visitors' entrance and at the wards, to rate compliance with the local guidelines in practice. Attitudes toward reopening and barriers and facilitators were studied, using a digital questionnaire (see Figure 1), based on a previous survey (Leontjevas et al. 2020) that was sent to nurses, psychologists, and physicians at the facilities. This questionnaire also contained questions regarding changes in well-being that had been observed after the lockdown. Finally, a convenience sample of visitors, nursing staff, management, and other stakeholders (e.g. occupational therapist, physician, catering staff) was interviewed with a structured interview guide regarding the experience of the visit, the compliance with local guidelines for the reopening, and the impact on the well-being of the residents, visitors, and care staff. The care organization informed all primary informal caregivers of the reopening and asked them to contact their loved one's unit to plan a visit. Subsequently, they were asked to participate in an interview after their first visit and to consent to being observed before and/or after the visit (not during).

\section{Data analysis}

Descriptive analyses were performed for responses to the digital questionnaire. Observations were 


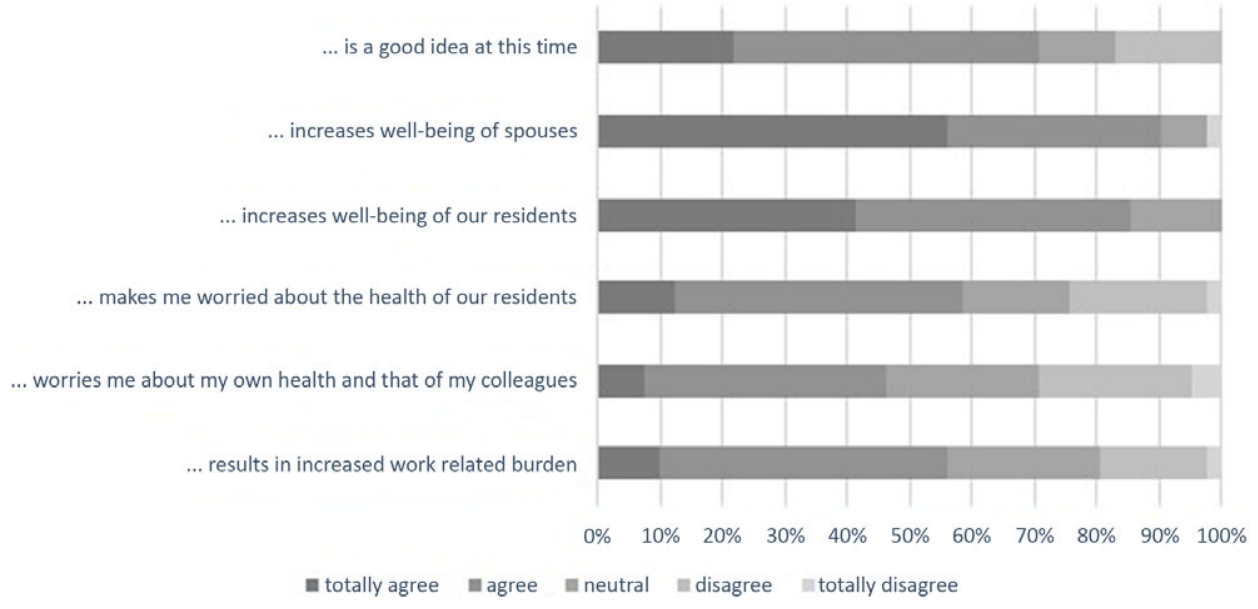

Figure 1. Barriers and facilitators regarding allowing visitors from the point of view of healthcare professionals $(n=46)$.

recorded in a logbook, on pre-structured observation forms, and summarized. Furthermore, interviews were tape recorded. Given the necessity of early reporting of the results to the Ministry of Health, Welfare and Sports, the interviews were not transcribed completely verbatim but summarized, thereby verbatim registering relevant quotes. Based on these summaries, using a structured format, deductive thematic content analysis was performed per location by each academic network separately. Subsequently, one of the research groups combined and analyzed the results of the five locations, after which all five research groups discussed and finalized the results.

\section{Ethical considerations}

The Medical Ethics Committee of the ArnhemNijmegen region approved the study protocol (2020-6549) and concluded that the study was not subject to the Medical Research Involving Human Subjects Act. Information about the study was provided via email to the interviewees and respondents of the digital questionnaire. Interviewees provided written and/or spoken informed consent for participation prior to the study. Participation was strictly voluntary, and participants were able to withdraw from the study at any moment. For early reporting to the ministry, we decided not to include residents in the data collection since this would require a more comprehensive and time-consuming review by the Medical Ethics Committee, especially because residents with dementia would be involved.

\section{Results}

Characteristics of the facilities and participants

The number of residents in the five facilities ranged from 68 to 130, with mostly mixed populations of residents with either dementia or predominant physical impairments (Table 1). Two facilities had no previous COVID-19-infected residents nor infected care staff. One facility had 11 infected residents and 6 infected members of the care staff. No new infections in residents or healthcare professionals were diagnosed during the 3 weeks of monitoring.

Forty-six healthcare professionals returned the digital questionnaire, of whom $26 \%$ were a physician or a psychologist, $33 \%$ were a nurse, $33 \%$ nurse assistants, and $8 \%$ had another profession. They had, on average, 13 years of working experience in long-term care.

A total of 73 visitors were interviewed, most of them $(63 \%)$ were female and the mean age was 61 years (range 25-84 years). Of the visitors, $67 \%$ were daughters/sons (in-law) and 19\% were husbands/wives.

Seventy-two healthcare professionals were interviewed, with most of them (90\%) being female, with a mean age of 39 years (range 16-64 years). Twentytwo percent were nurses (in training), $49 \%$ nurse assistants, $15 \%$ nurses aids (in training), and 14\% had another profession. Forty-three percent had more than 10 years of working experience.

\section{Feasibility of the regulations}

There was a broad diversity in local guidelines for allowing visitors (Table 2). All facilities allowed only one fixed visitor. The duration of visits ranged from $30 \mathrm{~min}$ to no limits at all. Most facilities required people to wear a face mask and measured the temperature to check fever, but gloves were mostly not required. After having been informed on May 6 that they were allowed to reopen on May 11, three of the five facilities were able to allow visitors from May 11 on. The other two started on May 12 and 13, respectively. In the first 3 weeks, a total of 445 residents had visitors. 
Table 1. Characteristics of the five facilities

\begin{tabular}{|c|c|c|c|c|c|}
\hline FACILITY & 1 & 2 & 3 & 4 & 5 \\
\hline Number of residents & 130 & 102 & 68 & 67 & 78 \\
\hline Number of units & 5 & 5 & 3 & 4 & 8 \\
\hline Type of units & $\begin{array}{l}\text { Dementia special care units } \\
\text { Units for residents with } \\
\text { physical impairments } \\
\text { Unit for short stay }\end{array}$ & $\begin{array}{l}\text { Dementia special care units } \\
\text { Units for residents with } \\
\text { physical impairments }\end{array}$ & $\begin{array}{l}\text { Dementia special care units } \\
\text { Units for residents with } \\
\text { physical impairments } \\
\text { Residential care }\end{array}$ & $\begin{array}{l}\text { Dementia special care units } \\
\text { Units for residents with } \\
\text { physical impairments } \\
\text { Residential care }\end{array}$ & $\begin{array}{l}\text { Dementia special care units } \\
\text { Units for residents with } \\
\text { physical impairments }\end{array}$ \\
\hline $\begin{array}{l}\text { Number of previous COVID- } \\
\text { 19-infected residents }\end{array}$ & 0 & 4 & 2 & 11 & 0 \\
\hline $\begin{array}{l}\text { Number of residents died of } \\
\text { COVID-19 }\end{array}$ & 0 & 4 & 1 & 3 & 0 \\
\hline $\begin{array}{l}\text { Number of COVID-19-in- } \\
\text { fected staff }\end{array}$ & 0 & 1 & 1 & 6 & 0 \\
\hline
\end{tabular}

Table 2. Characteristics of local guidelines for allowing visitors

\begin{tabular}{|c|c|c|c|c|c|}
\hline FACILITY & 1 & 2 & 3 & 4 & 5 \\
\hline Frequency of visits & $\begin{array}{l}\text { Once a week, and twice } \\
\text { when feasible }\end{array}$ & Once a week & Every day & Once a week & Once a week \\
\hline Duration of the visit & One hour & $\begin{array}{l}\text { One hour, later changed } \\
\text { to } 30 \mathrm{~min} \text { or } 1 \mathrm{~h}\end{array}$ & $\begin{array}{l}\text { No limits but end of the visit } \\
\text { before } 6 \text { PM }\end{array}$ & Thirty minutes & Forty-five minutes \\
\hline $\begin{array}{l}\text { Several (different) visitors } \\
\text { at once allowed? }\end{array}$ & No & No & No & No & No \\
\hline $\begin{array}{l}\text { Where does the visit } \\
\text { take place? }\end{array}$ & $\begin{array}{l}\text { Own apartment or } \\
\text { Special room }\end{array}$ & Own apartment & Own apartment & $\begin{array}{l}\text { Special room; later on changed } \\
\text { to own apartment }\end{array}$ & Own apartment \\
\hline Face mask obligatory? & $\begin{array}{l}\text { Yes, but not in the } \\
\text { special room }\end{array}$ & $\begin{array}{l}\text { Only for residents } \\
\text { with dementia }\end{array}$ & $\begin{array}{l}\text { Yes depending on the } \\
\text { residents' cognitive } \\
\text { capabilities }\end{array}$ & Yes & Yes \\
\hline Gloves obligatory? & $\begin{array}{l}\text { Yes, but not in the } \\
\text { special room }\end{array}$ & No & No & Yes; later on changed to no & No \\
\hline Temperature measurement? & Yes & Yes & Yes & No & Yes \\
\hline Allowed to leave the building? & No & No & No & No & No \\
\hline
\end{tabular}


Most of the professionals (49\%) who returned the digital questionnaire agreed that reopening at that time was a good idea and would certainly increase the well-being of the residents (85\%) and their spouses $(90 \%)$ (Figure 1). However, there were also great worries about increasing the workload (46\%) and negative impact on their own health and the residents' because of the increased risk.

The local regulations entailed new procedures for the care staff, while they hardly had any time to prepare themselves properly. As a result, in some facilities, care staff experienced a high workload, not only because of having to become acquainted with the new procedures but also because these procedures entailed extensive planning of the visits and guiding visitors to the residents. Visitors and care staff were generally satisfied with the information provided, although some experienced a lack of information:

'I didn't know beforehand that we had to disinfect our hands on every floor, but that is very understandable and not a problem.”

Compliance with the obligated visitor briefing regarding COVID-19-specific complaints and the routines of hand washing seemed to decrease during the 3 weeks of the monitoring. Care staff experienced barriers when instructing visitors and continuously pointing out the regulations. Some also expressed that it was the visitors' responsibility and not theirs. However, although most care staff relied on the amenability of the visitors, there were also some doubts:

\begin{abstract}
"You have to take people at their word. And I find that difficult because people will tell you all sorts of things because they are very keen to visit after all those weeks."
\end{abstract}

Compliance with keeping a social distance of $1.5 \mathrm{~m}$ was limited. Care staff estimated that almost half of the visitors touched the residents, gave them a hug or kissed, caressed them, or combed their hair.

"My father will not often take the initiative for a hug, but you can feel it, and he always made it clear, that he likes to have a hug. Ruffle his hair, or a hand on his shoulder. Some physical contact, person to person. I found that very difficult myself."

The face masks were often used incorrectly by visitors (upside down, inside out, or not covering nose and chin). Visitors also touched their face masks and did not like to wear them because it felt hot and very annoying for those with chronic obstructive pulmonary disease (COPD). In addition, face masks limited communication, especially with residents with hearing problems. Sometimes, face masks were unavailable for care staff and stored behind closed doors, because of shortages, even for those who experienced light COVID-19-like symptoms:

"But I keep hearing that the face masks are almost finished. That we should not overuse them."

The fact that care staff had to comply with other regulations than the visitors often resulted in dismay:

\begin{abstract}
"It is difficult when the care staff can be around my mum without a face mask, when they go shopping at the supermarket too. Their risk of catching the virus is the same as mine"
\end{abstract}

Visitors expressed great gratitude and joy about being able to visit their loved ones again, and therefore accepted the regulations easily. They preferred the visits over the previous alternatives such as window visits or video calls. Especially for residents with hearing problems or dementia, personal contact was easier and of a higher quality. However, wearing face masks or a visit in a designated room that was not the resident's limited these advantages.

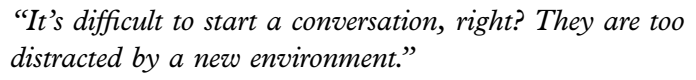

Furthermore, the quality of the contact suffered because it differed from previous routines. Social distancing, not being able to leave the building, go to a restaurant, or go out for a walk had a negative impact on the contact. The strict visiting hours and the limitation in duration all negatively influenced the quality of the contact. The fact that only one fixed visitor was allowed carried a great responsibility for that loved one/person.

\footnotetext{
"I actually wanted to go on holiday in a while, but now I'm thinking, well, I'm the only one, so ... And I think it's so sad that she has not seen anyone in so long. And now I want to go at least every other day, so I will stay at home for now. I'm not planning to go to the islands or anything like that."
}

\section{Impact on the well-being of residents, visitors, and healthcare professionals}

The professionals who returned the digital questionnaire had observed a decrease in the residents' wellbeing and an increase in the loneliness that they attributed to the lockdown (Figure 1).

\section{Resident well-being}

Overall, visitors and care staff noticed very positive responses in the residents; they enjoyed the visits, returned to the units in good spirits, and became more active. Some experienced sadness because physical contact was prohibited. Residents were longing for the next visit and wanted further easing 
of the regulations. However, most residents respected the rules.

\footnotetext{
"She was radiating happiness, she was so intensely happy to have a visitor [...] She was on cloud nine."

"Absolutely wonderful, but I did notice a trembling lip while saying goodbye."

"Before, I always used to hug and kiss her, also when I left, and that is quite a difference. [...] We are missing that now."

"They are already looking forward to the next visit. It was very different from before we closed; when it was obvious there would be visits. The value of having a visit is back."
}

In some residents with dementia, visits seemed to result in confusion, sadness, or restlessness. These visits provided too many stimuli, and some residents repeatedly asked where their loved one had gone or went searching for them. Sometimes, staff advised against visiting these residents anymore under the circumstances of that time.

"Now my whole life is upside down."

\section{Visitor well-being}

Almost all visitors were glad to be able to spend time with their loved ones again. Visiting was part of their role as informal caregivers and also included household activities like making a cup of coffee, doing the laundry, or checking finances. The residents own room provided an atmosphere of privacy, in which personal topics could be discussed, which was welcomed:

\footnotetext{
"But otherwise, I experienced it as very positive. The fact that I could be there again, that I could potter about, tidy up a little, organize a few things."

"No, I don't want to do that over the phone because I would not bring up these topics, and neither would my mother."
}

Many visitors expressed a sense of relief, seeing the residents in person and still being recognized by them. Some experienced the visit as confrontational, facing a decline of their family member, or expressed emotions of having missed valuable time together:

\footnotetext{
'So many emotions come to the surface, that you didn't know you had. At first, you think: I'll manage, it's all good, I can handle this reasonably well. Until something happens that you see each other. [...] So many emotions come to the surface then, that you weren't really ready for."
}

\section{Care staff well-being}

Care staff expressed an overall sense of ambivalence. On the one hand, they were very happy for the residents and visitors and noticed the positive impact on their well-being. It was also considered helpful that visitors took up their previous tasks again, such as watering the plants. On the other hand, they feared an increase of infections among residents, themselves, or their own family members. They wondered whether visitors complied with the regulations, were aware that they sometimes did not, and struggled with their responsibility in that respect. Some also doubted whether their colleagues complied with the hygiene measures:

\begin{abstract}
'I actually feel very sorry for the visitors, that they weren't allowed visits. And for the family too because, you know, they are in a care home and you don't know how long a person has to live. So, I think it's good that visits are allowed again."

"At first, I had my doubts about when it was announced that the visiting rules were being relaxed. I felt like ... we were sort of like guinea pigs. But now that I can see what it means to the residents, I am happy that they are allowed to see people again. I feel kind of ambivalent about it."
\end{abstract}

\section{Discussion}

To our knowledge, this is the first study that reports on in-depth experiences on the monitoring of allowing visitors into Dutch nursing homes after a lockdown due to COVID-19. It builds on the results of a previous paper reporting global monitoring of the first week after the reopening of 26 facilities (Verbeek, Gerritsen et al., 2020). We found that there was great variety in how national guidelines were translated into local care practice. Healthcare professionals agreed that reopening would benefit the well-being of the residents and their loved ones. However, there were also significant worries about increasing workload, leading to a risk of emotional exhaustion and the risk of COVID-19 infections (Sarabia-Cobo et al., 2020). Compliance with the local regulations was generally satisfactory, but social distancing and correctly wearing face masks appeared to be difficult. Care staff were still ambivalent for fear of infections. Allowing visitors were generally experienced as having a positive impact on the well-being of all stakeholders. Nevertheless, some residents with dementia showed adverse effects. Our results are in line with a recent international comparison of guidelines and emerging practices during the COVID-19 pandemic. The Netherlands, however, was the only country that mandated to reopen to visitors (Low et al., 2021).

On July 16, the Minister of Health, Welfare and Sports reported in a letter to the Dutch Parliament on the lessons learned from the COVID-19 crisis in nursing homes, in order to anticipate the second wave. One of the 10 issues that are addressed in this letter regarded allowing visitors. The minister stated that, although many alternative types of contact had been developed, there was no doubt that the lockdown had negatively impacted the residents' quality 
of life. Furthermore, the minister stated that, instead of a lockdown, a more tailored approach for individual facilities was warranted in case of an outbreak, with extensive testing and tracing, sufficient personal protective equipment (PPE), cohort care, and special COVID-19 units in or outside the nursing home to quarantine residents. The Dutch Parliament accepted a temporary legislation that was developed, the Corona Act, on October 13. It prohibited a complete lockdown of long-term care organizations in case of a COIVD-19 outbreak by guaranteeing every long-term care resident the right to have at least one visitor at all times. This approach of preventing a complete lockdown had already been recommended in the revised national regulations that were issued on September 17, 2020. The Dutch regulations are also in line with the recently published regulations from Canada (Bergman et al., 2020).

The impact of not allowing more than one visitor to residents in need of palliative care was heavily debated in particular during the first wave. This policy was criticized as being inhumane and not ethically justifiable. While the second wave is currently ongoing, policies in that respect have changed dramatically. Almost all respondents to a recent global monitoring in 76 facilities (report in Dutch and handed over to the Dutch Ministry of Health, Welfare and Sports on October 16), indicated that visitors should always be allowed to visit their dying loved one.

This study had some limitations. The five participating facilities were members of one of the academic networks of nursing homes and may therefore not be representative of all Dutch long-term care facilities, thus limiting external validity. Given the need for publication of the results during the pandemic, and the fact that transcribing the interviews and subsequently coding and analyzing these using more established methods would require about 9 months extra, it was decided to refrain from doing so and use the described methods instead. In addition, we were not able to interview the residents themselves. Thus, there is a risk of bias regarding the impact on the well-being of the residents because this is judged by the visitors and the care staff. The need for early reporting was also the reason that we were not able to study associations in differences between our outcomes and the local guidelines as listed in Table 2.

Since the beginning of June, the national lockdown of Dutch nursing homes has been gradually ended, and facilities without COVID-19 infections returned to the "new normal" of social distancing at $1.5 \mathrm{~m}$ and applying hygiene measures in the nursing homes, without further restrictions to the number of visitors. This still limits visitors and residents in a certain sense, because resident rooms or apartments are sometimes too small to allow more than one or two visitors at a time; larger gatherings, such as celebrating birthdays with the entire family, are also limited.

In conclusion, the complete lockdown of Dutch nursing homes had a substantial impact on the wellbeing of the residents. The reopening was welcomed by all stakeholders, but provided a high organizational workload, as well as feelings of ambivalence among care staff. This is in line with the findings of another Dutch study (Sizoo et al., 2020) that although nursing homes reopened their doors, care staff still faced dilemmas in finding a tailored and person-centered approach serving the needs of all involved. During the second wave, which is currently affecting more than $32 \%$ of the Dutch long-term care facilities, a more tailored approach is being implemented. Unfortunately, to date, this approach had again to be adapted because of new regulations as a result of a complete lockdown of the country (since December 15) limiting the number of visitors currently to one per day for each Dutch household and each resident in care homes. Again, facilities are challenged to find the right balance between infection control and well-being (Dichter et al., 2020). In that respect, it is good to know that the Dutch Government started vaccinating all nursing home residents on January 18.

\section{Conflict of interest}

None.

\section{Source of funding}

Ministry of Health, Welfare and Sports.

\section{Acknowledgments}

We thank all the co-researchers without whom this study would not have been completed in such a short timeframe: Marleen Lovink, Charlotte van Corven, Eline van Buuren, Caroline Tittelbach, Henny van der Weide, Sander Ranke (Radboudumc), Lizette Wattel, Marja Depla, Corien Bosveld, Annelie Monier (Amsterdam UMC), Judith Urlings, Ramona Backhaus, Bram de Boer, Eveline van Velthuijsen, Johanna Rutten, Erica de Vries (Maastricht University), Annerieke Stoop, Katrien Luijkx (Tilburg University), Sytse Zuidema (UMC Groningen).

\section{Contributions of authors}

Raymond Koopmans, Debby Gerritsen, Annemiek Bielderman, Anke Persoon, Hilde Verbeek, and Jan Hamers designed the study, participated in data collection and analysis, and co-authored the 
manuscript. Ivonne Lesman-Leegte, Meriam Janssen, and Eefje Sizoo participated in data collection and analysis, and co-authored the manuscript.

\section{References}

Appelhof, B. et al. (2018). Process evaluation of an intervention for the management of neuropsychiatric symptoms in young-onset dementia. Fournal of the American Medical Directors Association, 19, 663-671. https:// doi.org/10.1016/j.jamda.2018.02.013

Bergman, C. et al. (2020). Recommendations for welcoming back nursing home visitors during the COVID19 pandemic: results of a Delphi panel. Fournal of the American Medical Directors Association, 21, 1759-1766. https://doi.org/10.1016/j.jamda.2020.09.036

Car, J., Koh, G. C., Foong, P. S. and Wang, C. J. (2020). Video consultations in primary and specialist care during the covid-19 pandemic and beyond. BMF, 371, m3945. https://doi.org/10.1136/bmj.m3945

Dichter, M. N., Sander, M., Seismann-Petersen, S. and Köpke, S. (2020). COVID-19: it is time to balance infection management and person-centered care to maintain mental health of people living in German nursing homes. International Psychogeriatrics, 32, 1157-1160. https://doi .org/10.1017/S1041610220000897

Hwang, T.-J., Rabheru, K., Peisah, C., Reichman, W. and Ikeda, M. (2020). Loneliness and social isolation during the COVID-19 pandemic. International Psychogeriatrics, 32, 1217-1220. https://doi.org/10.1017/ S1041610220000988

Koopmans, R. T. C. M., Lavrijsen, J. C. M. and Hoek, F. (2013). Concrete Steps Toward Academic Medicine in Long Term Care. Fournal of the American Medical Directors Association, 14, 781-783. https://doi.org/10.1016/j.jamda .2013 .08 .004

Leontjevas, R., Gerritsen, D. L., Koopmans, R. T., Smalbrugge, M. and Vernooij-Dassen, M. J. (2012). Process evaluation to explore internal and external validity of the "Act in Case of Depression" care program in nursing homes. Fournal of the American Medical Directors Association, 13, 488 e481-488. https://doi.org/10.1016/j .jamda.2012.03.006

Leontjevas, R. et al. (2020). Challenging behavior of nursing home residents during COVID-19 measures in the Netherlands. Aging E Mental Health, 1-6. https://doi.org/ 10.1080/13607863.2020.1857695

Low, L. F. et al. (2021) Safe visiting at care homes during COVID-19: A review of international guidelines and emerging practices during the COVID-19 pandemic. LTCcovid.org, International Long-Term Care Policy Network, CPEC-LSE, 19th January 2021.

Padala, S. P., Jendro, A. M. and Orr, L. C. (2020) Facetime to reduce behavioral problems in a nursing home resident with Alzheimer's dementia during COVID-19. Psychiatry Research, 288, 113028. https://doi.org/10.1016/j .psychres.2020.113028

Rutten, J. J. S., van Loon, A. M., Joling, K. J., Smalbrugge, M., van Buul, L. W. and Hertogh, C. (2020). [COVID-19 in nursing homes A study of diagnosis, symptomatology and disease course]. Nederlands
Tijdschrift voor Geneeskunde, 164. (Covid-19 in verpleeghuizen.)

Sarabia-Cobo, C. et al. (2020). Experiences of geriatric nurses in nursing home settings across four countries in the face of the COVID-19 pandemic. Fournal of Advanced Nursing. https://doi.org/10.1111/jan. 14626

Simonetti, A. et al. (2020). Neuropsychiatric symptoms in elderly with dementia during COVID-19 pandemic: definition, treatment, and future directions. Front Psychiatry, 11, 579842. https://doi.org/10.3389/fpsyt.2020.579842

Sizoo, E. M., Monnier, A. A., Bloemen, M., Hertogh, C. M. P. M. and Smalbrugge, M. (2020). Dilemmas with restrictive visiting policies in Dutch nursing homes during the COVID-19 pandemic: a qualitative analysis of an openended questionnaire with elderly care physicians. Fournal of the American Medical Directors Association, 21, 1774 1781.e1772. https://doi.org/10.1016/j.jamda.2020.10.024

Van der Roest, H. G. et al. (2020). The impact of COVID19 measures on well-being of older long-term care facility residents in the Netherlands. Fournal of the American Medical Directors Association, 21, 1569-1570. https://doi.org/ 10.1016/j.jamda.2020.09.007

Velayudhan, L., Aarsland, D. and Ballard, C. (2020). Mental health of people living with dementia in care homes during COVID-19 pandemic. International Psychogeriatrics, 32, 1253-1254. https://doi.org/10.1017/ S1041610220001088

Verbeek, H., Gerritsen, D. L., Backhaus, R., de Boer, B. S., Koopmans, R. and Hamers, J. P. H. (2020). Allowing visitors back in the nursing home during the COVID-19 crisis: A Dutch National Study into first experiences and impact on well-being. Fournal of the American Medical Directors Association, 21, 900-904. https:// doi.org/10.1016/j.jamda.2020.06.020

Verbeek, H., Zwakhalen, S. M. G., Schols, J., Kempen, G. and Hamers, J. P. H. (2020). The living lab in ageing and long-term care: a sustainable model for translational research improving quality of life, quality of care and quality of work. The Fournal of Nutrition, Health $\mathcal{E}$ Aging, 24, 43-47. https:// doi.org/10.1007/s12603-019-1288-5

Verbeek, H., Zwakhalen, S. M., Schols, J. M. and Hamers, J. P. (2013). Keys to successfully embedding scientific research in nursing homes: a win-win perspective. Fournal of the American Medical Directors Association, 14, 855-857. https:// doi.org/10.1016/j.jamda.2013.09.006

Wammes, J. D., Kolk, D., van den Besselaar, J. H., MacNeil-Vroomen, J. L., Buurman-van, B. M. and van Rijn, M. (2020). Evaluating perspectives of relatives of nursing home residents on the nursing home visiting restrictions during the COVID-19 crisis: A Dutch CrossSectional Survey Study. Fournal of the American Medical Directors Association, 21, 1746-1750.e1743. https://doi .org/10.1016/j.jamda.2020.09.031

Wang, H. et al. (2020). Dementia care during COVID-19. Lancet, 395, 1190-1191. https://doi.org/10.1016/S01406736(20)30755-8

Yu, B., Steptoe, A., Chen, L. J., Chen, Y. H., Lin, C. H. and Ku, P. W. (2020). Social Isolation, Loneliness, and All-Cause Mortality in Patients With Cardiovascular Disease: A 10-Year Follow-up Study. Psychosomatic Medicine, 82, 208-214. https://doi.org/10.1097/PSY .0000000000000777 